\title{
Molecular surveillance and phylogenetic traits of Babesia bigemina and Babesia bovis in cattle (Bos taurus) and water buffaloes (Bubalus bubalis) from Colombia
}

Jeiczon Jaimes-Dueñez ${ }^{1}$ Omar Triana-Chávez ${ }^{1}$, Andrés Holguín-Rocha², Alberto Tobon-Castaño² and Ana M. Mejía-Jaramillo ${ }^{1 *}$ (D)

\begin{abstract}
Background: Babesia bigemina and B. bovis are two economically important hemoparasites affecting both cattle and buffaloes involved in dairy and beef production. In Colombia, although some parasitological and serological studies suggest an endemicity of these pathogens in areas under $1000 \mathrm{~m}$, little is known about its molecular prevalence in different host. The objective of this study was to estimate the prevalence and molecular traits of these parasites in cattle and buffaloes from two Colombian regions.

Methods: Between 2014 and 2016, a three-point longitudinal survey was designed in farms from Caribbean and Orinoquia regions to evaluate the molecular prevalence of $B$. bigemina and B. bovis using a nested PCR (n-PCR) targeting hypothetical protein (hyp) and rhoptry-associated protein (RAP-1) genes, respectively. A total of 1432 cattle, 152 buffalo and 1439 Rhipicephalus microplus samples were analyzed. Moreover, phylogenetic relationship of isolates was analyzed using the 185 rRNA gene.

Results: A molecular prevalence of 31.6\% (24.2\% for B. bigemina and 14.4\% for B. bovis), 23.6\% (6.5\% for B. bigemina and $17.7 \%$ for B. bovis) and $4.3 \%$ (3.5\% for B. bigemina and $1.0 \%$ for B. bovis) was observed in cattle, buffaloes and Rhipicephalus microplus, respectively. Higher values of infection were observed during the wet season and late wet season; nevertheless, other variables such as age, production type, sex, breed and babesiosis control were also significantly associated with infection. Prevalence analysis showed that $B$. bovis infection was higher in cattle that coexist with buffaloes, when compared to those which did not. For each species, phylogenetic analyses revealed a high genetic diversity of isolates without clusters related to the isolation source.

Conclusions: To our knowledge, this is the first longitudinal survey that evaluates through molecular methods, the infection of $B$. bigemina and $B$. bovis in two important livestock regions from Colombia. This study reveals that the prevalence of infection by Babesia spp., in cattle and buffaloes are modulated by seasonal variations, host factors and vector traits. Our results provide new insights on the epidemiological aspects of infection of Babesia spp., in cattle and buffaloes, which must be taken into consideration when babesiosis control programs are implemented in the study area.
\end{abstract}

Keywords: Babesia, Colombia, nPCR, Cattle, Water buffaloes

\footnotetext{
* Correspondence: anamejia25@gmail.com

${ }^{1}$ Grupo BCEl, Universidad de Antioquia UdeA, Calle 70 No. 52-21, Medellín,

Colombia

Full list of author information is available at the end of the article
}

(c) The Author(s). 2018 Open Access This article is distributed under the terms of the Creative Commons Attribution 4.0 International License (http://creativecommons.org/licenses/by/4.0/), which permits unrestricted use, distribution, and reproduction in any medium, provided you give appropriate credit to the original author(s) and the source, provide a link to the Creative Commons license, and indicate if changes were made. The Creative Commons Public Domain Dedication waiver (http://creativecommons.org/publicdomain/zero/1.0/) applies to the data made available in this article, unless otherwise stated. 


\section{Background}

Babesiosis, caused by species of the genus Babesia, intraerythrocytic apicomplexan parasites, is a worldwide tick-borne hemoprotozoosis affecting many domestic and wild mammalian species. Two species are present in South America, Babesia bovis and B. bigemina, which are epidemiologically important in livestock and are biologically transmitted by the cattle tick Rhipicephalus microplus [1, 2]. Cattle with babesiosis usually show severe clinical signs that include fever, anemia, jaundice, loss of appetite, muscle tremors, haemoglobinuria and death [3], while in buffaloes clinical cases are rare and hardly associated with clinical signs such as fever, colic, anorexia and haemoglobinuria [4]. Although B. bigemina is more widespread, causing mortality rates up to $30 \%$ in animals without treatment, $B$. bovis is the most virulent Babesia parasite, generating mortality rates between $70-80 \%$, as a result of the related neurological signs [5].

In Colombia, tick-borne diseases produce economic losses of approximately 4.2 million USD per year, and they affect mainly the cattle farms on the Atlantic coast, the Andean valleys, and the Orinoquia region, representing more than half of the national livestock population $[6,7]$. Previous parasitological surveys of Babesia spp. carried out in these regions showed a prevalence of 1.1$3.8 \%$ in cattle [8-10], and $4.6-30.1 \%$ in buffaloes [11, 12], suggesting an important role of the latter host in maintaining the circulation of these pathogens. In Colombia the buffalo population is increasing with an annual growth up to $35 \%$, most of them bred in the same pastures alongside the cattle [13]. In this sense, studies that evaluate the epidemiology and molecular features of Babesia spp. in both hosts have not been yet performed, ignoring whether the differences in the infection rate may be due to epidemiological conditions from study areas or to the particular traits of isolates in both hosts.

Although in South America several studies have shown seasonal variations of $R$. microplus [14, 15], in Colombia little is known about these variations in the infection rates of Babesia spp. in the livestock. Therefore, the aim of this study was to evaluate the transmission dynamic and genetic features of the causal agents of babesiosis in cattle and buffaloes from the Atlantic coast and Orinoquia regions, in order to understand the epidemiology of this disease in Colombian livestock and to contribute to more efficient control strategies.

\section{Methods}

\section{Study area}

The study was conducted from October 2014 to March 2016 on ten farms of the Antioquia department (A-J) (Fig. 1a) and ten farms of Arauca (K-T) (Fig. 1b), which represented 11.7 and $4.6 \%$ of the national livestock population, respectively [6]. The inclusion criteria for the farms included animal age records and restriction for the entry of livestock from other farms. The farms of Antioquia were located in the municipalities of Necoclí and Turbo in the Caribbean region, at altitudes under $8 \mathrm{~m}$, with an annual biotemperature average of $26{ }^{\circ} \mathrm{C}$ and rainfall of $2400 \mathrm{~mm}$, distributed over a dry season from January to March, a wet season from April to September, and a late wet season from October to December [16]. The farms of Arauca were located in the municipalities of Arauquita, Saravena and Tame in the Orinoquía region in the east of the country, at altitudes under $231 \mathrm{~m}$, with an annual biotemperature average of $27^{\circ} \mathrm{C}$ and rainfall of $2500 \mathrm{~mm}$, distributed over a dry season from November to March, a wet season from April to July, and a late wet season from August to October [16].

Ninety-five percent of the farms employ extensive farming systems, where animals are fed with Brachiaria spp. and native grasses, and are at densities of 1.314 (SD $=0.359$ ) livestock units (LUs) per hectare (ha), and the rest use the intensive farming system. The main species of cattle is Bos indicus, with breeds such as the Brahman, Gyr and Guzerat, and its crosses with $B$. taurus, including breeds such as Limousin, Brown Swiss and Holstein Friesians. For buffaloes, the main species is Bubalus bubalis, with breeds such as Carabao, Mediterranean, Murrah and their crosses. Babesiosis control is mainly based on vector control carried out with insecticides and acaricides such as avermectins, organophosphates and pyrethroids, as well as the use of antiprotozoal drugs such as imidocarb dipropionate and diminazine accurate. Additional information about the geographical location and characteristics of each farm is shown in Additional file 1: Table S1.

\section{Study design}

According to previous epidemiological studies concerning seasonal variations of $R$. microplus and its relationship with transmission patterns of babesiosis [14, 17], a three-point longitudinal survey was designed to examine seasonal variations of Babesia spp. infection in the study area in cattle, buffaloes and ticks during the dry season, wet season and the late wet season.

\section{Sample size}

The sample size was calculated using Epi Info ${ }^{\text {тм }} 7.0$, taking into account the number of cattle or buffalo in the farms of each department, a $22.5 \%$ probability of being infected according to Herrera et al. [9], a 95\% confidence interval and a statistical error of $5 \%$. Thus, the estimated sample size for cattle in each season was 220 and 260, in Arauca and Antioquia, respectively, while for buffaloes was 148 for Antioquia. Within each farm, the samples were collected randomly, considering the percentage of animals $\leq$ 1 year-old and $>1$ year-old according to Amorim et al. 


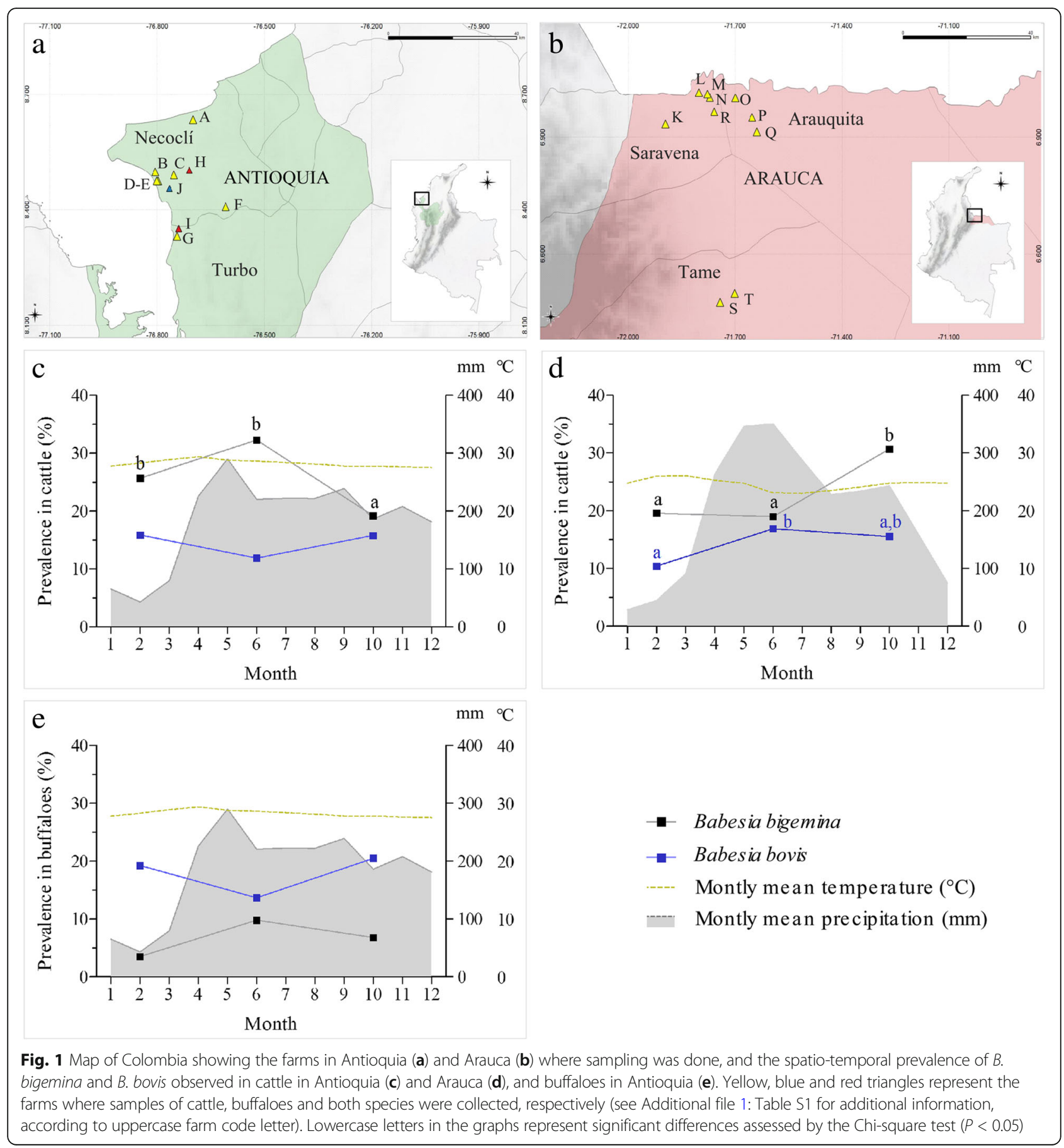

[18]. Cattle samples were collected on nine farms of Antioquia (A-I) (Fig. 1a) and ten farms of Arauca (K-T) (Fig. 1b), whereas buffalo samples were collected on three farms in Antioquia (H-J) (Fig. 1a).

\section{Blood sample collection and proccessing}

For each animal, $5 \mathrm{ml}$ of blood was collected from the coccygeal or jugular vein using EDTA.K3 Vacutainer tubes (Improve Medical, Guangzhou, China) and stored at $4{ }^{\circ} \mathrm{C}$ until processing. Additional information about the number of samples collected in each farm during each sampling is detailed in Additional file 1: Table S1. Blood samples were transferred within $6 \mathrm{~h}$ after collection into a glass micro-hematocrit capillary tube containing Na-heparin (80 IU/ml) (Vitrex Medical, Copenhagen, Denmark), sealed at one end with Cristaseal (Hawksley, Lancing, UK) and centrifuged for $5 \mathrm{~min}$ at $9000 \times \mathrm{rpm}$ at room temperature, to measure the packed cell volume $(\mathrm{PCV})$ in 
a micro-hematocrit capillary tube reader (Bacto, Sydney, Australia). Genomic DNA was extracted from $200 \mu \mathrm{l}$ of blood using the Genomic DNA Purification Kit (Invisorb, Birkenfeld, Germany) according to the manufacturer's instructions. Total DNA was diluted with $100 \mu \mathrm{l}$ of elution buffer and stored at $-20^{\circ} \mathrm{C}$ until molecular diagnosis.

\section{Tick sample collection and processing}

Between 5 and 20 ticks were collected from the highly infested animals selected for blood sampling along with others located on the same farms, using entomological forceps through examination of the perineum surface according to Baker \& Ducasse [19]. All collected specimens were directly preserved in $70 \%$ ethanol and stored at $4{ }^{\circ} \mathrm{C}$ until processing. Tick samples were initially examined under a stereomicroscope (Leica Microsystems, Mannheim, Germany) and classified up to the species, sex and life stage according to morphological keys reported for ticks of veterinary importance in South America [20]. After that, specimens were grouped in pools of one to six individuals based on their life stage, sex, species and mammalian host. Considering that a positive correlation between the blood parasite levels of infected animals and the numbers of Babesia kinetes in the hemolymph of the dropped tick has been shown [21, 22], hemolymph DNA from each pool of ticks was extracted as detailed below. To that end, ticks were washed three times in $70 \%$ ethanol for $5 \mathrm{~min}$ to sterilize them [23], and subsequently, the legs were dissected in PBS as reported elsewhere [24]. This material was frozen and disrupted mechanically in liquid nitrogen [25] and then subjected to genomic DNA extraction using a DNeasy Blood \& Tissue Kit (Qiagen, Hilden, Germany) according to the manufacturer's instructions. Total DNA was diluted with $100 \mu \mathrm{l}$ of elution buffer and stored at $-20{ }^{\circ} \mathrm{C}$ until molecular diagnosis.

\section{Screening for the presence of $B$. bigemina and $B$. bovis}

All DNA preparations were screened to test for the presence of B. bigemina and B. bovis using a nested PCR (n-PCR) targeting the hypothetical protein (hyp) and rhoptry associated protein (RAP-1) genes, respectively [26], which have been reported with a specificity of $100 \%$ and an analytical sensitivity corresponding to parasitemias of approximately $3.0 \times 10^{-2}$ and $1.7 \times 10^{-2}$ parasites $/ \mu$ l of the infected blood, respectively [27]. The oligonucleotide sequences used in the present study and their annealing temperatures are shown in Table 1. All PCR assays were conducted in $25 \mu \mathrm{l}$ reactions containing $1 \times$ reaction buffer $(100 \mathrm{mM}$ Tris- $\mathrm{HCl}, 50 \mathrm{mM} \mathrm{KCl}, \mathrm{pH}$ 8.8), $0.2 \mathrm{mM} \mathrm{dNTP}, 1.5 \mathrm{mM} \mathrm{MgCl} 2,0.4 \mu \mathrm{M}$ of each primer, 0.625 UI of Taq DNA polymerase (Thermo Scientific, Massachusetts, USA), and $5 \mu \mathrm{l}(100 \mathrm{ng})$ of DNA samples for the first PCR and $1 \mu \mathrm{l}$ of PCR product for the second. PCR products were analyzed by $2 \%$ agarose gel electrophoresis, stained with GelRed (Thermo Fisher Scientific) and visualized under UV light. Sample preparations were considered positive for $B$. bigemina or $B$.

Table 1 List of primers used in PCR assays

\begin{tabular}{|c|c|c|c|c|c|c|}
\hline Organism & Target gene & Primer & Oligonucleotide sequence $\left(5^{\prime}-3^{\prime}\right)$ & Amplicon size (bp) & Annealing $\mathrm{T}\left({ }^{\circ} \mathrm{C}\right)$ & $\overline{\text { Reference }}$ \\
\hline \multirow[t]{4}{*}{ B. bigemina } & hyp & BilA & CATCTAATTTCTCTCCATACCCCTCC & 278 & 63 & [26] \\
\hline & & BilB & CCTCGGCTTCAACTCTGATGCCAAAG & & & \\
\hline & & BilAN & CGCAAGCCCAGCACGCCCCGGTGC & 170 & 70 & \\
\hline & & BilBN & CCGACCTGGATAGGCTGTGTGATG & & & \\
\hline \multirow[t]{4}{*}{ B. bovis } & RAP-1 & BoF & CACGAGGAAGGAACTACCGATGTTGA & 350 & 61 & [26] \\
\hline & & BoR & CCAAGGAGCTTCAACGTACGAGGTCA & & & \\
\hline & & BoFN & TCAACAAGGTACTCTATATGGCTACC & 290 & 67 & \\
\hline & & BoRN & CTACCGAGCAGAACCTTCTTCACCAT & & & \\
\hline \multirow[t]{2}{*}{ Babesia spp. } & 185 rRNA & $A$ & ACCTGGTTGATCCTGCCAG & $\sim 1700$ & 60 & [30] \\
\hline & & B & GATCCTTCTGCAGGTTCACCTAC & & & \\
\hline \multirow[t]{2}{*}{ B. bigemina } & 185 rRNA & Bbig200F & GCGTTATTAGTTCGTTAACC & $\sim 1200$ & 56 & [32] \\
\hline & & Bbig1400R & ACAGGACAAACTCGATGGATGC & & & \\
\hline \multirow[t]{2}{*}{ B. bovis } & 185 rRNA & AN & GCTTGTCTTAAAGATTAAGCCATGC & $\sim 1550$ & 60 & [31] \\
\hline & & $\mathrm{BN}$ & CGACTTCTCCTTCCTITAAGTGATAAG & & & \\
\hline \multirow[t]{2}{*}{ Mammalian } & cyt b & Cyt bF & CCCCTCAGAATGATATTTGTCCTCA & $\sim 383$ & 60 & [28] \\
\hline & & Cyt bR & CCATCCAACATCTCAGCATGATGAAA & & & \\
\hline \multirow[t]{2}{*}{ Insects } & $\operatorname{cox} 1$ & LCOI490 & GGTCAACAAATCATAAAGATATTGG & $\sim 710$ & 45 & [29] \\
\hline & & $\mathrm{HCO} 2198$ & TAAACTTCAGGGTGACCAAAAAATCA & & & \\
\hline
\end{tabular}


bovis when a band of 170 or $290 \mathrm{bp}$, respectively, was observed in the electrophoresis of the second PCR. To confirm the specificity of the molecular diagnosis, the PCR product of one positive sample of B. bigemina and one of $B$. bovis were purified and sequenced using the Sanger method at Macrogen, Korea.

Finally, to check the presence of PCR inhibitors and amplifiable DNA, a 383 bp fragment from the $c y t b$ gene from mammals [28], and a 710 bp fragment from the cox 1 gene of arthropods [29], were amplified by PCR in all negative blood and tick samples, respectively (Table 1). Samples that did not amplify were excluded from the data analysis.

\section{Amplification and sequencing of genetic markers}

After molecular diagnosis, the strongest positive samples for the amplification of hyp and $R A P-1$ genes were selected to amplify the $18 S$ rRNA gene from $B$. bigemina and $B$. bovis. The complete $18 S$ rRNA gene of both species was initially amplified by PCR using oligonucleotides A and B [30], and $1 \mu \mathrm{l}$ of PCR product was used as template in the n-PCR using oligonucleotides set AN/ BN [31], and Bbi200F/Bbi1400R [32] for each species, respectively. The amplified fragments were separated in $2 \%$ agarose gels stained with GelRed (Thermo Fisher Scientific), excised from the gels, purified by a Zymoclean $^{\text {tw }}$ Gel DNA Recovery Kit (Zymo Research, Irvine, CA, USA) and cloned using the pGEM-T Easy vector system (Promega, Wisconsin, USA) according to the manufacturer's instructions. One to two clones from each isolate were purified and completely sequenced in both strands using the Sanger method at Macrogen.

\section{Phylogenetic analyses}

Sequences were aligned using CLUSTALW [33] as implemented in BioEdit v.7.1.9 [34]. For each species, phylogenetic analyses were performed using sequences obtained in this study along with reference sequences of Babesia spp. derived from cattle, buffaloes and vaccination strains from America and other continents. Each alignment was analyzed using the Maximum Composite Likelihood method with Kimura 2-parameters model in MEGA6.0 software. Internal branch confidence was assessed by the boot-strapping method using 1000 bootstrap replicates. The trees were drawn with FigTree v.1.4.2 (Institute of Evolutionary Biology, University of Edinburgh, UK).

\section{Data source}

The environmental dataset used in this study corresponded to monthly values of precipitation $(\mathrm{mm})$ and mean temperature $\left({ }^{\circ} \mathrm{C}\right)$ from 2011 to 2016 in the study areas, which were provided by the Institute of Hydrology, Meteorology and Environmental Studies of Colombia
(IDEAM). The meteorological stations (12045010, 12030020 and 12025030) from Antioquia and those of Arauca (36030030, 37045010 and 36025010) were chosen according to their proximity to the study farms.

\section{Data analysis}

To construct models that could explain the dependent variable (B. bigemina or $B$. bovis infection) as a function of 11 qualitative independent variables related to host and environmental conditions (Additional file 1: Table S2), generalized estimated equation (GEE) models were run using a binomial distribution, a $\log$ link function and exchangeable interclass correlation. In all analyses the feature farm was included as the group variable. Initially, the independent variables were subjected to univariate analysis. Those with a statistical association (here considered to be $P<0.25$, Chi-square test, according to Hosmer \& Lemeshow [35]) were tested in the multivariate model using a stepwise method. The level of statistical significance of the variables included in the multivariate model was set at $P<0.05$. The results are expressed as Exp (B) (an estimate of the prevalence ratio, $\mathrm{PR}$ ) and 95\% CI. Additional prevalence comparisons were performed using the Chi-square test.

The cut-off to determine anemic cattle and buffaloes was $\mathrm{PCV} \leq 24 \%$ and $\leq 29 \%$, respectively, according to described by Abd Ellah et al. [36] and Rockett \& Bosted [37]. Finally, the relationship between Babesia spp. prevalence in both mammalian hosts with the age was evaluated through correlation analysis, after a ShapiroWilk normality test. $P<0.05$ was considered significant. The sizes of age groups varied from 4 to $12 \%$ of the total population. Data analyses were performed using SPSS v.18.0 statistical software.

\section{Results \\ Babesia spp. infection is modulated by host and environmental conditions}

A total of 1432 cattle (715 from Arauca and 717 from Antioquia) and 152 buffaloes were analyzed, which corresponded to 75.0 and $79.6 \%$ of animals $>1$ year-old, with a mean age of $4.69(\mathrm{SD}=3.64)$ and 6.42 years $(\mathrm{SD}$ = 5.96), respectively. Of the total cattle analyzed, 31.6\% $(453 / 1432)$ were positive for Babesia spp. of which $24.2 \%(347 / 1432)$ and $14.4 \%(207 / 1432)$ were positive for B. bigemina and B. bovis, respectively. For buffaloes, 23.6\% (36/152) were positive for Babesia spp. of which $6.5 \%(10 / 152)$ and $17.7 \%(27 / 152)$ were positive for each species, respectively. The prevalence of co-infections $(B$. bigemina + B. bovis) for cattle and buffaloes was $7.0 \%$ $(101 / 1432)$ and $0.6 \%(1 / 152)$ (Table 2$)$, respectively.

Interestingly, during the three samplings, $B$. bigemina was the most prevalent species for cattle (Fig. 1c, d), 
Table 2 Prevalence of Babesia bigemina and Babesia bovis determined by molecular techniques in cattle, buffaloes and ticks from Colombia, during dry, wet and late wet seasons

\begin{tabular}{|c|c|c|c|c|c|c|c|c|}
\hline \multirow[t]{2}{*}{ Detected pathogens } & \multicolumn{2}{|c|}{ Dry season } & \multicolumn{2}{|c|}{ Wet season } & \multicolumn{2}{|c|}{ Late wet season } & \multicolumn{2}{|c|}{ Annual } \\
\hline & $n$ & Positive (\%) & $n$ & Positive (\%) & $n$ & Positive (\%) & $n$ & Positive (\%) \\
\hline \multicolumn{9}{|l|}{ B. bigemina } \\
\hline Cattle & 466 & $105(22.5)$ & 463 & $118(25.4)$ & 503 & $124(24.6)$ & 1432 & $347(24.2)$ \\
\hline Buffaloes & 57 & $2(3.5)$ & 51 & $5(9.8)$ & 44 & $3(6.8)$ & 152 & $10(6.5)$ \\
\hline R. microplus (pools) & 45 & $2(4.4)$ & 23 & $0(0.0)$ & 210 & $8(3.8)$ & 278 & $10(3.5)$ \\
\hline D. nitens (pools) & 7 & - & - & - & 4 & $0(0)$ & 11 & $0(0)$ \\
\hline A. cajennense (s.l.) (pools) & - & - & - & - & 9 & $0(0)$ & 9 & $0(0)$ \\
\hline \multicolumn{9}{|l|}{ B. bovis } \\
\hline Cattle & 466 & $61(13.0)$ & 463 & $67(14.4)$ & 503 & $79(15.7)$ & 1432 & $207(14.4)$ \\
\hline Buffaloes & 57 & $11(19.3)$ & 51 & $7(13.7)$ & 44 & $9(20.5)$ & 152 & $27(17.7)$ \\
\hline R. microplus (pools) & 45 & $0(0)$ & 23 & $0(0)$ & 210 & $3(1.4)$ & 278 & $3(1.0)$ \\
\hline D. nitens (pools) & 7 & - & - & - & 4 & $0(0)$ & 11 & $0(0)$ \\
\hline A. cajennense (s.l.) (pools) & - & - & - & - & 9 & $0(0)$ & 9 & $0(0)$ \\
\hline \multicolumn{9}{|l|}{ B. bigemina + B. bovis } \\
\hline Cattle & 466 & $25(5.3)$ & 463 & $35(7.5)$ & 503 & $41(8.1)$ & 1432 & $101(7.0)$ \\
\hline Buffaloes & 57 & $0(0)$ & 51 & $0(0)$ & 44 & $1(2.2)$ & 152 & $1(0.6)$ \\
\hline R. microplus (pools) & 45 & $0(0)$ & 23 & $0(0)$ & 210 & $1(0.4)$ & 278 & $1(0.3)$ \\
\hline
\end{tabular}

while for buffaloes B. bovis was most prevalent (Fig. 1e). The highest Babesia spp. prevalence values for both cattle and buffaloes were observed during the wet season or late wet season, with significant seasonal variations found in cattle from both departments (Fig. 1c, d). B. bovis infection was higher in cattle that coexist with buffaloes, when compared to those who did not $(P<0.05)$ (Fig. 2).

In cattle, PCV analyses showed a mean of $33.7 \%$ (SD = 5.7\%), 29.6\% (SD = 6.4\%) and 31.1\% (SD = 6.01\%) for Bos indicus, $B$. taurus and their crosses, respectively, while for buffaloes the mean PCV was $33.5 \%$ (SD $=7.13 \%$ ). A proportion of $8.9 \%(123 / 1379)$ and $33.5 \%(51 / 152)$ of cattle and buffaloes showing anemia signs was observed, respectively. Both B. bigemina and B. bovis prevalence was higher in animals with normal PCV values than those with anemia signs (Additional file 1: Table S2). Significant negative Pearson's correlation coefficients (Spearman's $r=$ $-0.674, P=0.008$ ) was observed between Babesia spp. prevalence and the age range in cattle, with lower prevalence of infection in older animals (Fig. 3a). On the contrary, no significant correlation was observed in the case of buffaloes (Fig. 3b). All cattle and buffalo negative samples amplified cyt $b$ gene. Finally, the hyp gene 128 bp derived from Arauca's cattle (Additional file 2: nucleotide sequence) showed $95 \%$ identity with scaffold 71,030 of the B. bigemina genome (LK055111.1), while the $267 \mathrm{bp}$ of the RAP-1 gene from Antioquia's cattle (KX365053) showed $100 \%$ identity with the R1A strain of $B$. bovis identified in Argentina (AF030062.1).

\section{Molecular analysis detected a low infection rate of Babesia spp. in R. microplus}

Of 1479 ticks collected from 216 bovines across the three sampling periods in both departments, $97.2 \%$ (1439/1479) corresponded to $R$. microplus, $1.8 \%$ (27/ $1479)$ to Dermacentor nitens and $0.9 \%$ (13/1479) to Amblyoma cajennense (sensu lato). Regarding life stages, $97.5 \%$ of $R$. microplus samples were adults $(89.6 \%$ females and $10.4 \%$ males) and $2.5 \%$ nymphs; for D. nitens $88.9 \%$ were adults (100\% females) and $11.1 \%$ nymphs, while for A. cajennense (s.l.) $60.0 \%$ were adults (100\% females) and $40.0 \%$ nymphs. Of the total of pools of $R$. microplus analyzed, 4.3\% (12/278) were positive for $\mathrm{Ba}$ besia spp. of which 3.5\% (10/278), 1.0\% (3/278) and 0.3\% $(1 / 278)$ were positive for B. bigemina, B. bovis, and co-infected, respectively (Table 2). All positive pools corresponded to engorged female, without significant differences in the infection rate between both departments. $D$. nitens and $A$. cajennense (s.l.) were negative for both $B$. bigemina and $B$. bovis. All ticks negative samples had an amplified $\operatorname{cox} 1$ gene.

\section{Babesia spp. infection in cattle and buffaloes is influenced by different variables}

In univariate analysis, the detection of at least one Babesia spp--positive cattle by molecular techniques was statistically associated $(P<0.25)$ with all independent variables, except for breed, PCV, sampling season and department for B. bigemina; and breed, sampling season, department, farming system and vector control for $B$. 


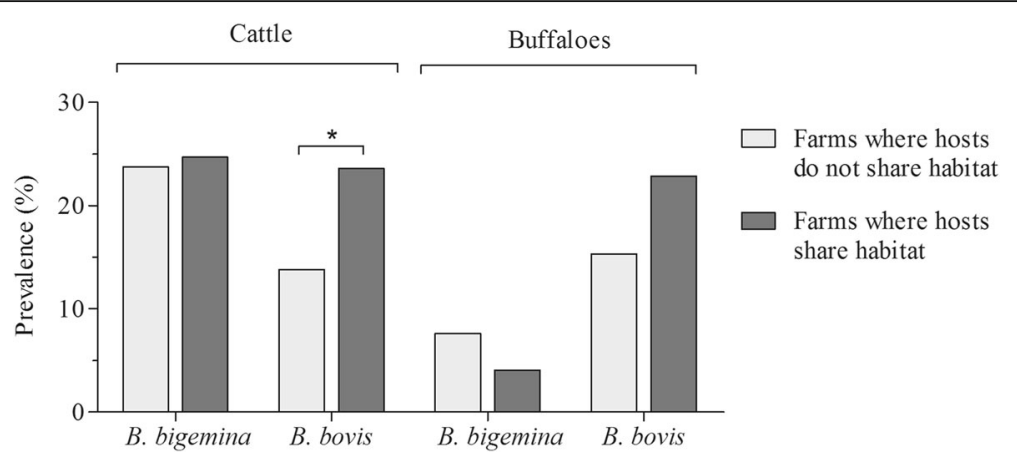

Fig. 2 Comparison of the prevalence of B. bigemina and B. bovis in animals who did not share habitat (cattle or buffaloes) compared with animals sharing habitat (cattle and buffaloes). ${ }^{*}$ Significant differences assessed by the Chi-square test $(P<0.05)$

bovis (Additional file 1: Table S2). However, in the multivariate analysis, only age and production type, were significantly associated $(P<0.05)$ with the infection of both $B$. bovis and B. bigemina (Fig. 4a).

For the case of buffaloes, univariate analysis showed statistical associations $(P<0.25)$ of Babesia spp. infection with all independent variables except for sex, PCV, sampling season, ambiental temperature, babesiosis control and municipality for B. bigemina; and PCV, sampling season, ambient temperature and production type for B. bovis (Additional file 1: Table S2). However, in the multivariate analysis, only sex and production type were significantly associated $(P<0.05)$ with the infection of $B$. bigemina, and breed and babesiosis control were significantly associated with the infection of B. bovis (Fig. 4b).

\section{Phylogenetic analyses of Babesia spp. do not show differentiation between isolation sources}

A total of 10 (MH194385-MH194394) sequences of $B$. bigemina derived from PCR products cloned into the pGEM-T Easy vector system (Promega) from 4 cattle, 5 buffaloes and 1 pool of ticks ( $R$. microplus), and 13 (MH194395-MH194407) sequences of B. bovis from 8 cattle and 5 buffaloes were analyzed. Both $B$. bigemina and $B$. bovis phylogenetic trees showed clusters with high proximity of the Colombian isolates to world isolates derived from different hosts. Moreover, clusters related to each isolation source were not observed in each species (Fig. 5a, b).

\section{Discussion}

Babesia bigemina and B. bovis are the two economically important species affecting livestock farms involved in dairy and beef production in Colombia [1, 10, 12]. Given the paucity of studies on the distribution and characterization of these pathogens in different mammalian hosts, control strategies have been unsuccessful. To our knowledge, this is the first longitudinal survey and molecular characterization of B. bigemina and B. bovis in cattle and buffaloes from livestock areas in Colombia to consider eco-epidemiological variables associated with infection; this can improve the epidemiological understanding and control strategies of babesiosis in this country.

The results reported herein demonstrate that in the study area, the two Babesia species exhibited differences in prevalence between the mammalian hosts studied, with B. bigemina being most prevalent in cattle $(24.2 \%)$ and $B$. bovis in buffaloes (17.7\%). Similar results were observed in

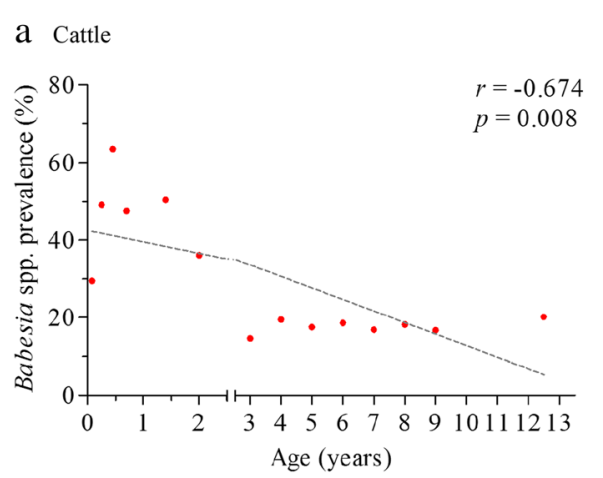

b Buffaloes

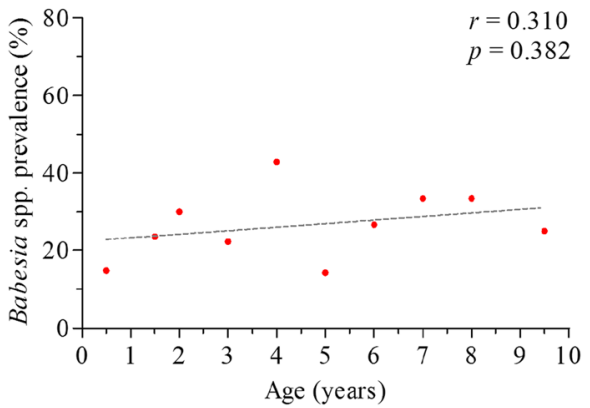

Fig. 3 Correlation analysis between the prevalence of Babesia spp. and age groups of cattle (a) and buffaloes (b) from the study area. A significant negative Pearson's correlation coefficient $(r=-0.674)$ was observed for cattle 


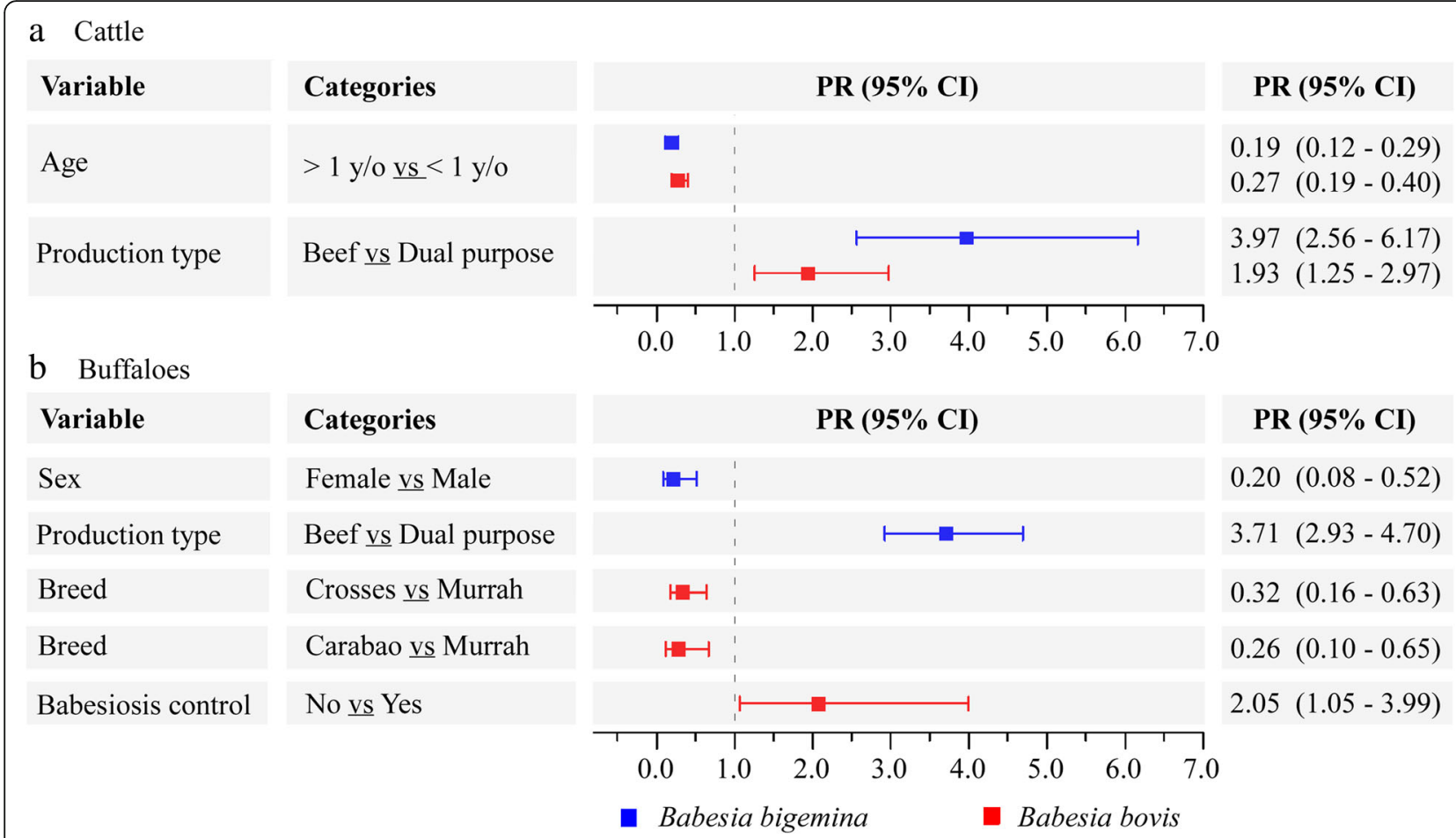

Fig. 4 Forest plot of prevalence ratio (PR) obtained from the multivariate model (GEE) of infection with B. bigemina and B. bovis in cattle (a) and buffaloes (b) from Colombia. All prevalence ratios of independent variables are discriminated by category comparison. Squares and horizontal bars represent PRs and $95 \% \mathrm{Cls}$, respectively

livestock areas from Argentina, Brazil and Colombia, in which the molecular prevalence of $B$. bigemina and $B$. bovis in cattle was $46.4 \pm 7.0 \%$ and $11.7 \pm 3.6 \%$, respectively $[10,18,38-40]$, while in buffaloes it was $8.6 \pm 7.6 \%$ and $17.5 \pm 8.8 \%$ for each species, respectively [41-43]. These findings, together with those obtained from the spatio-temporal analysis, in which these proportions did not vary with time (Fig. 1c-e), suggest that South American buffalo populations tend to support a higher prevalence of $B$. bovis compared to cattle populations.

The $18 S$ rRNA gene has been previously used to identify genetic clusters of Babesia spp. associated with specific hosts [32]. Considering the paucity of phylogenetic studies of Babesia spp. in livestock from South America, a phylogenetic approach to Colombian isolates was applied. Interestingly, our results showed that Babesia spp. isolates derived from cattle and buffaloes are not associated with particular clusters, suggesting a lack of genetic structure in these isolates and a possible circulation of strains between both hosts. These results, together with the higher prevalence of $B$. bovis observed in cattle coexisting with buffaloes (Fig. 2), support the idea that buffaloes might act as reservoir hosts for the infection of $B$. bovis in cattle. Therefore, special management measures have to be taken to prevent economic losses related to infection of this pathogen in cattle populations such as decreasing the tick transfer between cattle and buffaloes on farms with both hosts, as well as sharing of needles between them. On the other hand, the lack of genetic structure could be due to a variability of apicomplexan parasites that has been proposed as a survival strategy against the vertebrate immune response [44-46]. In this sense, genetic diversity observed here could be associated with continuous immune pressure by both hosts. Nevertheless, other factors, such as multiple introductions of strains from various geographical locations, and the diversity of biological and mechanical vectors, could also explain this behavior.

According to Smith et al. [47] enzootic stability of $\mathrm{Ba}$ besia spp. is maintained when at least $75 \%$ of the herd is infected before nine months of age. On this matter, experimental and epidemiological studies in South America have provided evidence for significant differences between molecular and serological diagnosis of Babesia spp. showing that prevalence is two to three times more in indirect-ELISA compared to PCR analysis [41, 48]. Thus, the active infection rate detected by molecular methods in cattle under six months old (>60\%) together with the lack of anemic signs associated (Fig. 3a), suggest an enzootic stability in this population, as observed in other livestock areas from Colombia [10, 12, 49]. However, future studies using serological test are necessary to confirm the enzootic stability in the study area. 


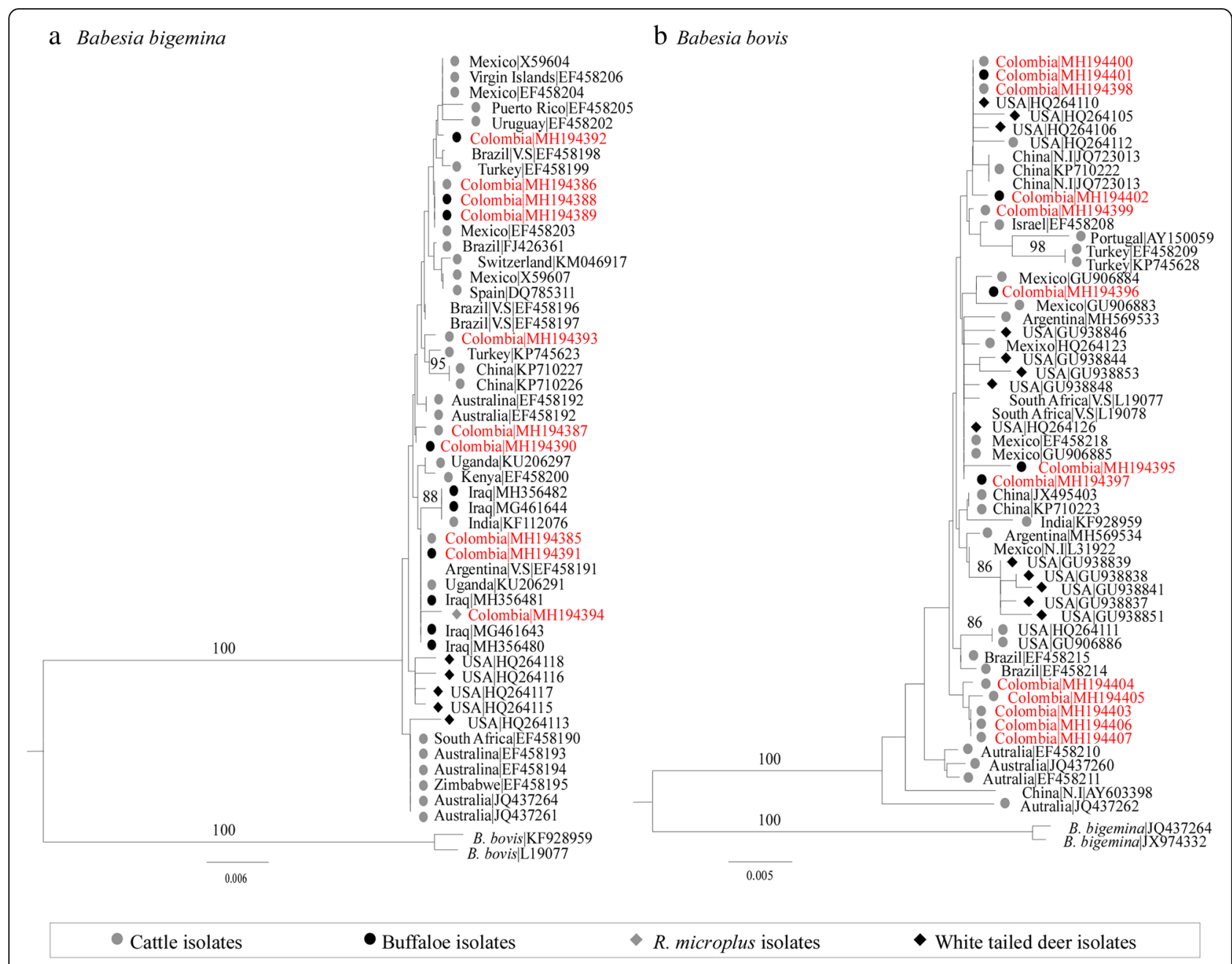

Fig. 5 Maximum likelihood tree based on 185 rRNA genes of B. bigemina (a) and B. bovis (b) isolates. Taxa in red represent the sequences of isolates reported in this paper. Node support bootstrap values $>80 \%$ are shown on the branches. Abbreviations: N.I, non-identified source; V.S, vaccination strain

Although buffaloes did not show clinical signs associated with infection, the prevalence was variable between age groups (Fig. $3 \mathrm{~b}$ ), as previously observed in endemic areas of South America [11, 50]. In Colombia, like in other South American countries, buffalo populations have increased notably during recent years from approximately 100,000 buffaloes in 2010 to 250,000 in $2016[6,13]$. This is mainly due to changing approaches towards meat and milk production, and to the perception that buffaloes are more tolerant than cattle to infection with Babesia spp. and the subsequent acute clinical effects resulting from such infections [51, 52]. This tendency, which included movement of animals to new areas with different transmission rates, could explain the heterogeneous dynamic of the prevalence in the age groups and the lack of clinical signs observed in these hosts; nevertheless, the low number of farms and blood samples evaluated for this species and the use of molecular techniques also could explain these results.
In Colombia, ecological studies that evaluated the dynamics of $R$. microplus at altitudes under $600 \mathrm{~m}$ showed that high infestation rates in cattle were observed in the days after the rain peaks, when the humidity and temperature conditions were optimal for the development of all tick life stages $[53,54]$. Interestingly, our results showed that although B. bigemina and B. bovis were found during all samplings, seasonal variations were observed, with high frequencies detected during wet and late wet season in both hosts (Fig. 1c-e). This suggests that ticks and babesiosis control systems should be intensified during these seasons to reduce the economic impact resulting from outbreaks associated with the high transmission of these pathogens during the humid months.

In South America, little is known about the infection rates of Babesia spp., established by molecular methods, in $R$. microplus. Epidemiological studies that evaluated this feature in endemic areas from Brazil $[27,55]$ and 
Colombia [40], showed molecular infection rates ranging between $16.8-88.6 \%$. Surprisingly, our results showed that infection rates in $R$. microplus were lower than 5.0\% during all samplings (Table 2), indicating a discrepancy with those previously reported. Given that samples analyzed in previous studies correspond to DNA obtained from the whole body of the specimen, it is likely that infestation rates detected by them correspond to parasite stages or DNA present in the midgut, and not specifically to parasites in the hemolymph of the female tick. However, other factors such as levels of parasitemia in the hosts, which can modulate the infection rates in tick populations [21], as well as differences in the sensitivity of molecular diagnostic methods, cannot be ruled out. With regard to the high proportion of $B$. bigemina detected in the hemolymph compared to B. bovis (Table 2), this may be due to the ability of $B$. bigemina to remain through generations of Rhipicephalus spp. in the absence of reinfection, which does not happen in B. bovis [21, 56]; nevertheless, the high degree of pathogenicity of $B$. bovis in cattle, which lead to parasitemia less that $1 \%$ during acute infection [57], may also explain these results.

Although, the Babesia spp. infection is mainly associated with tick exposure $[2,55]$, its dynamics is complex and depends on many factors, whose association determines the prevalence of infection in the livestock. Herein, we identified different variables related to Babesia spp. infection, which could be modulating the prevalence of infection in the study area. In cattle, both $B$. bigemina and $B$. bovis infection were specifically associated with the age and production type (Fig. 4a). As discussed previously, the lower probability of adults of being infected with Babesia spp. when compared to calves is explained by the apparent enzootic stability in the study area, in which the higher infection rate observed in calves give rise to a fully protected adult herd with little chance of developing clinical signs against new infections $[48,58]$. In the same way, the significantly higher infection rate of Babesia spp. observed in young animals can be explained by the fact that they have a softer skin compared to adults, which facilities the mouth-part penetration of the vector, making them the preferred host of ticks [59]. These findings, together with the low infection rate of Babesia spp. detected in ticks and the poor transovarial transmission of these pathogens in $R$. microplus $(<50 \%)[21,60]$ suggest that a high tick infestation rate in young cattle is necesary to produce the high infection rate detected in this age group. On the other hand, the protective effect observed both in cattle and buffaloes dedicated to dual-purpose (Fig. 4a, b) suggest that frequent hygiene practices and tendency to use adult females in this group, could explain their low prevalence compared with those dedicated only to beef production. As a consequence, improving the implementation of vector and vector-borne pathogen control systems in animals dedicated to beef production will prevent sporadic outbreaks of babesiosis in these productions type. Finally, other variables such as sex, breed and babesiosis control were differentially associated with Babesia spp. infection in buffaloes (Fig. 4b). These findings showing a higher probability of infection in males, animals of the Murrah breed, and those kept on farms without babesiosis control systems, could encourage farmers from the study area to intensify these in buffalo populations.

\section{Conclusions}

To our knowledge, this is the first epidemiological study investigating the spatio-temporal prevalence of $B$. bovis and B. bigemina in cattle, buffaloes and ticks, from two important livestock areas of Colombia. Our results revealed that the prevalence of infection by Babesia spp., in cattle and buffaloes are modulated by seasonal variations, host factors and vector traits. Furthermore, while in cattle the infection occurs under enzootic stability, in buffaloes it could be associated with an enzootic instability, accompanied by a high prevalence of $B$. bovis which suggests an important role of these animals as possible reservoir hosts of infection for cattle.

\section{Additional files}

Additional file 1: Table S1. Geographical location and characteristics of the farms evaluated in Antioquia and Arauca, Colombia. Table S2. Bivariate model of infection with Babesia spp., in livestock herds from Antioquia and Arauca, Colombia. (DOCX 58 kb)

Additional file 2: Nucleotide sequences derived from a hypothetical protein of Babesia bigemina. (FAS $1 \mathrm{~kb}$ )

\section{Abbreviations}

rRNA: Ribosomal ribonucleic acid; SD: Standard deviation

\section{Funding}

This research was supported by the Universidad de Antioquia (UdeA). JJD was supported by a fellowship from COLCIENCIAS.

\section{Availability of data and materials}

Data supporting the conclusions of this article are included within the article and its additional files. The raw data of this study are available from the corresponding author upon reasonable request. Representative sequences were submitted to the GenBank database under the accession numbers KX365053, MH194385-MH194407.

\section{Authors' contributions}

Conceived and designed the experiments: JJD, OTC, ATC and AMJ.

Performed the experiments: JJD and AHR. Analyzed the data: JJD and AHR. Wrote the paper: JJD, OTC and AMJ. All authors read and approved the final manuscript.

\section{Ethics approval}

Animal work was approved by the authorities of the Ethics Committee for Animal Experimentation of the University of Antioquia (authorization no. 18084). All in vivo procedures were performed in respect to the law 84 of 1989 and 576 of 2000 established by Ministry of National Education from 
Colombia. The arthropods capture was regulated by the National Environmental Licensing Authority of Colombia (ANLA).

\section{Consent for publication \\ Not applicable.}

\section{Competing interests}

The authors declare that they have no competing interests.

\section{Publisher's Note}

Springer Nature remains neutral with regard to jurisdictional claims in published maps and institutional affiliations.

\section{Author details}

'Grupo BCEl, Universidad de Antioquia UdeA, Calle 70 No. 52-21, Medellín, Colombia. ${ }^{2}$ Grupo Malaria, Universidad de Antioquia UdeA, Calle 70 No. 52-21, Medellín, Colombia.

Received: 18 May 2018 Accepted: 31 August 2018

Published online: 12 September 2018

\section{References}

1. Alonso M, Arellano-Sota C, Cereser VH, Cordoves CO, Guglielmone AA, Kessler R, et al. Epidemiology of bovine anaplasmosis and babesiosis in Latin America and the Caribbean. Rev Sci Tech. 1992;11:713-33.

2. Chauvin A, Moreau E, Bonnet S, Plantard O, Malandrin L. Babesia and its hosts: adaptation to long-lasting interactions as a way to achieve efficient transmission. Vet Res. 2009:40:37.

3. Merck S, Dohme C. Babesiosis. In: The Merck Veterinary Manual; 2017. https://www.msdvetmanual.com/circulatory-system/blood-parasites/ babesiosis. Accessed 1 May 2017

4. Patel PA, Modi LC, Chaudhary PM, Patel SP, Joshi AH. A rare case of babesiosis in Mehsana Buffalo. IJAVMS. 2011;5:383-4.

5. Kaufmann J. Parasitic Infections of Domestic Animals: A Diagnostic Manual. Basel-Boston-Berlin: Birkhauser; 1996.

6. ICA. Instituto Colombiano de Agricultura - Censo Pecuario Nacional 2016. Bogota: Instituto Colombiano de Agricultura (ICA); 2016.

7. Vizcaíno OG, Benavides EO. Vacuna colombiana contra anaplasmosis y babesiosis bovinas: la alternativa más eficaz y económica para el control de estos hemoparasitismos. Corpoica. 2004:1:2-11.

8. Blanco R, Cardona J, Vargas M. Prevalencia de parásitos hematrópicos endoglobulares en bovinos gyr puros en Córdoba, Colombia. Rev Med Vet. 2016;31:67-74

9. Herrera M, Soto A, Urrego V, Rivera G, Zapata M, Rios M. Frequency of hemoparasites of bovines from Cauca and San Jorge Rivers, 2000-2005. Rev MVZ Córdoba. 2008;13:1486-94.

10. Jaimes-Dueñez J, Triana-Chávez O, Mejía-Jaramillo AM. Parasitological and molecular surveys reveal high rates of infection with vector-borne pathogens and clinical anemia signs associated with infection in cattle from two important livestock areas in Colombia. Ticks Tick Borne Dis. 2017;8:290-9.

11. Cardona JA, Hoyos CE, Garay OV. Frecuencia de hematrópicos en tres explotaciones de búfalos (Bubalus bubalis) del Departamento de Córdoba, Colombia. FCV-LUZ. 2012;22:530-6.

12. Ríos L, Zapata R, Reyes J, Mejía J, Baena A. Estabilidad enzoótica de babesiosis bovina en la región de Puerto Berrío, Colombia. FCV-LUZ. 2010;20:485-92.

13. ICA. Líbano es el nuevo mercado para búfalos colombianos. Bogotá: Instituto Colombiano Agropecuario; 2016.

14. Lima WS, Ribeiro MF, Guimaraes MP. Seasonal variation of Boophilus microplus (Canestrini, 1887) (Acari: Ixodidae) in cattle in Minas Gerais State, Brazil. Trop Anim Health Prod. 2000;32:375-80.

15. Mangold AJ, Aguirre DH, Gaido AB, Guglielmone AA. Seasonal variation of ticks (Ixodidae) in Bos taurus $\times$ Bos indicus cattle under rotational grazing in forested and deforested habitats in northwestern Argentina. Vet Parasitol. 1994:54:389-95.

16. IDEAM. Atlas climatológico de Colombia. Bogotá: Instituto de Hidrología, Meteorología y Estudios Ambientales; 2014

17. Quintão-Silva MG, Ribeiro MF. Infection rate of Babesia spp. sporokinetes in engorged Boophilus microplus from an area of enzootic stability in the State of Minas Gerais, Brazil. Mem Inst Oswaldo Cruz. 2003;98:999-1002.
18. Amorim LS, Wenceslau AA, Carvalho FS, Carneiro PL, Albuquerque GR. Bovine babesiosis and anaplasmosis complex: diagnosis and evaluation of the risk factors from Bahia, Brazil. Rev Bras Parasitol Vet. 2014;23:328-36.

19. Baker M, Ducasse F. Tick infestation of livestock in Natal. I. The predilection sites and seasonal variations of cattle ticks. J South Afr Vet Assoc. 1967;38:447-53.

20. Barros-Battesti D, Arzua M, Bechara G. Carrapatos de importancia medico veterinaria da regiao neotropical: Um guia ilustrado para identificaçao de especies. São Paulo: IDTTD-3, Butanta; 2006.

21. Howell JM, Ueti MW, Palmer GH, Scoles GA, Knowles DP. Transovarial transmission efficiency of Babesia bovis tick stages acquired by Rhipicephalus (Boophilus) microplus during acute infection. J Clin Microbiol. 2007;45:426-31.

22. Howell JM, Ueti MW, Palmer GH, Scoles GA, Knowles DP. Persistently infected calves as reservoirs for acquisition and transovarial transmission of Babesia bovis by Rhipicephalus (Boophilus) microplus. J Clin Microbiol. 2007; 45:3155-9.

23. Mitsuhashi J. Invertebrate Tissue Culture. Tokyo: Springer; 2002. p. 358-68.

24. Patton TG, Dietrich G, Brandt K, Dolan MC, Piesman J, Gilmore RD. Saliva, salivary gland, and hemolymph collection from Ixodes scapularis ticks. J Vis Exp. 2012;21:3894.

25. Rodríguez I, Fraga J, Noda JA, Mayet M, Duarte Y, Echevarria E, et al. An alternative and rapid method for the extraction of nucleic acids from ixodid ticks by potassium acetate procedure. Braz Arch Biol Technol. 2014;57:542-7.

26. Figueroa JV, Chieves LP, Johnson GS, Buening GM. Multiplex polymerase chain reaction based assay for the detection of Babesia bigemina, Babesia bovis and Anaplasma marginale DNA in bovine blood. Vet Parasitol. 1993;50:69-81.

27. Oliveira-Sequeira TC, Oliveira MC, Araujo JP, Amarante AF. PCR-based detection of Babesia bovis and Babesia bigemina in their natural host Boophilus microplus and cattle. Int J Parasitol. 2005:35:105-11.

28. Boakye DA, Tang J, Truc P, Merriweather A, Unnasch TR. Identification of bloodmeals in haematophagous Diptera by cytochrome B heteroduplex analysis. Med Vet Entomol. 1999;13:282-7.

29. Folmer M, Black W, Hoeh R. Vrijenhoek R. DNA primers for amplication of mitochondrial cytochrome c oxidase subunit I from diverse metazoan invertebrates. Mol Mar Biol Biotechnol. 1994;3:294-9.

30. Sogin M. Amplification of ribosomal RNA genes for molecular evolution studies. In: Innis MA, Gelfand DH, Sninsky JJ, White TJ, editors. PCR-Protocols: A Guide to Methods and Applications. London: Academic Press; 1990.

31. Schoelkopf L, Hutchinson CE, Bendele KG, Goff WL, Willette M, Rasmussen JM, et al. New ruminant hosts and wider geographic range identified for Babesia odocoilei (Emerson and Wright 1970). J Wildl Dis. 2005;41:683-90.

32. Holman PJ, Carroll JE, Pugh R, Davis DS. Molecular detection of Babesia bovis and Babesia bigemina in white-tailed deer (Odocoileus virginianus) from Tom Green County in central Texas. Vet Parasitol. 2011;177:298-304.

33. Thompson J, Gibson T, Plewniak F, Jeanmougin F, Higgins D. The ClustalX windows interface: Xexible strategies for multiple sequence alignment aided by quality analysis tools. Nucleic Acids Res. 1997:25:4876-82.

34. Hall T. BioEdit: a user-friendly biological sequence alignment editor and analysis program for Windows 95/98/NT. Nucleic Acids Symp Ser. 1999; 41:95-8.

35. Hosmer D, Lemeshow S. Applied Logistic Regression. 2nd ed. New York: Wiley; 2005

36. Abd Ellah MR, Hamed Ml, Ibrahim DR, Rateb HZ. Serum biochemical and haematological reference intervals for water buffalo Bubalus bubalis heifers. J South Afr Vet Assoc. 2014:85:962.

37. Rockett J, Bosted S. Veterinary Clinical Procedures in Large Animal Practice (Veterinary Technology). Boston: Cengage Learning; 2007.

38. Canever MF, Vieira LL, Reck C, Richter L, Miletti LC. First evaluation of an outbreak of bovine babesiosis and anaplasmosis in southern Brazil using multiplex PCR. Korean J Parasitol. 2014:52:507-11.

39. Paoletta MS, López Arias L, de la Fournière S, Guillemi EC, Luciani C, Sarmiento NF, et al. Epidemiology of Babesia, Anaplasma and Trypanosoma species using a new expanded reverse line blot hybridization assay. Ticks Tick Borne Dis. 2017:9:155-63.

40. Ríos-Tobón S, Gutiérrez-Builes L, Ríos-Osorio L. Assessing bovine babesiosis in Rhipicephalus (Boophilus) microplus ticks and 3 to 9-month-old cattle in the middle Magdalena region, Colombia. Pesqui Vet Bras. 2014;34:313-9.

41. da Silva JB, André MR, da Fonseca AH, de Albuquerque Lopes $C T$, da Silva Lima DH, de Andrade SJ, et al. Molecular and serological prevalence of Babesia bovis and Babesia bigemina in water buffaloes in the north region of Brazil. Vet Parasitol. 2013;197:678-81. 
42. Ferreri L, Benitez D, Dominguez M, Rodriguez A, Asenzo G, et al. Water buffalos as carriers of Babesia bovis in Argentina. Ann N Y Acad Sci. 2008; 1149:149-51.

43. Silveira JAG, de Oliveira CHS, Silvestre BT, Albernaz TT, Leite RC, Barbosa JD, et al. Molecular assays reveal the presence of Theileria spp. and Babesia spp. in Asian water buffaloes (Bubalus bubalis, Linnaeus, 1758) in the Amazon region of Brazil. Ticks Tick Borne Dis. 2016;7:1017-23.

44. Jackson AP, Otto TD, Darby A, Ramaprasad A, Xia D, Echaide IE, et al. The evolutionary dynamics of variant antigen genes in Babesia reveal a history of genomic innovation underlying host-parasite interaction. Nucleic Acids Res. 2014;42:7113-31.

45. Silva JC, Cornillot E, McCracken C, Usmani-Brown S, Dwivedi A, Ifeonu OO, et al. Genome-wide diversity and gene expression profiling of Babesia microti isolates identify polymorphic genes that mediate host-pathogen interactions. Sci Rep. 2016;6:35284.

46. Guillemi E, Ruybal P, Lia V, González S, Farber M, Wilkowsky SE. Multi-locus typing scheme for Babesia bovis and Babesia bigemina reveals high levels of genetic variability in strains from Northern Argentina. Infect Genet Evol. 2013;14:214-22.

47. Smith RD, Evans DE, Martins JR, Ceresér VH, Correa BL, Petraccia C, et al. Babesiosis (Babesia bovis) stability in unstable environments. Ann N Y Acad Sci. 2000:916:510-20.

48. da Silva J, dos Santos P, Fonseca A. Molecular and serological detection of Babesia bovis and Babesia bigemina in cattle in the Rio de Janeiro, Brazil. Semin Cienc Agrar. 2014;35:3139.

49. Zapata R, Ramírez N, Zapata A, Vélez J, Osorio L. Seroprevalencia de babesiosis bovina en la hacienda Vegas de la Clara, Gómez Plata (Antioquia), 2008. Rev Med Vet. 2011;21:63-71.

50. Néo T, Giglioti R, Obregón D, Bilhassi T, Oliveira H, Machado R. Detection of Babesia bovis and Babesia bigemina in water buffaloes (Bubalus bubalis) in endemic areas of São Paulo state, Brazil. Open J Vet Med. 2016;6:75-84.

51. Mahmmod Y. Natural Babesia bovis infection in water buffaloes (Bubalus bubalis) and crossbred cattle under field conditions in Egypt: a preliminary study. J Arthropod Borne Dis. 2014;8:1-9.

52. Mingala CN, Konnai S, Cruz LC, Onuma M, Ohashi K. Comparative moleculoimmunological analysis of swamp-and riverine-type water buffaloes responses. Cytokine. 2009;46:273-82.

53. Aycardi E, Benavides E, Garcia O, Mateus G, Henao F, Zuluaga FN. Boophilus microplus tick burdens on grazing cattle in Colombia. Trop Anim Health Prod. 1984;16:78-84.

54. Salazar R. Variación de la población de garrapatas Rhipicephalus microplus sobre bovinos pastoreando en sistemas silvopastoriles y monocultivos tradicionales. 2017. http://www.bdigital.unal.edu.co/54614/1/32183129.2015. pdf. Accessed 1 May 2017.

55. Oliveira MC, Oliveira-Sequeira TC, Regitano LC, Alencar MM, Néo TA, Silva AM, et al. Detection of Babesia bigemina in cattle of different genetic groups and in Rhipicephalus (Boophilus) microplus tick. Vet Parasitol. 2008; 155:281-6.

56. Dalgliesh RJ, Stewart NP. Some effects of time, temperature and feeding on infection rates with Babesia bovis and Babesia bigemina in Boophilus microplus larvae. Int J Parasitol. 1982;12:323-6.

57. Rolls PJ, Bock RE, de Vos AJ, Waldron SJ. Bovine babesiosis. OIE manual of diagnostic tests and vaccine for terrestrial animals. Babesiosis bovina. Paris: Work Organisation for Animal Health (OIE); 2012.

58. Mahoney DF, Ross DR. Epizootiological factors in the control of bovine babesiosis. Aust Vet J. 1972;48:292-8.

59. Kabir M, Mondal M, Eliyas M, Mannan M, Hashem M, Debnath N, et al. An epidemiological survey on investigation of tick infestation in cattle at Chittagong District, Bangladesh. Afr J Microbiol Res. 2011;5:346-52.

60. Cafrune MM, Aguirre DH, Mangold AJ, Guglielmone AA. Experimental studies of the rate of infection of Boophilus microplus eggs with Babesia bovis. Res Vet Sci. 1995;58:284-5.

Ready to submit your research? Choose BMC and benefit from:

- fast, convenient online submission

- thorough peer review by experienced researchers in your field

- rapid publication on acceptance

- support for research data, including large and complex data types

- gold Open Access which fosters wider collaboration and increased citations

- maximum visibility for your research: over $100 \mathrm{M}$ website views per year

At BMC, research is always in progress.

Learn more biomedcentral.com/submissions 